\title{
Genomic Analyses of Visual Cognition: Perceptual Rivalry and Top-Down Control
}

\author{
ํㅡㄹiqing Chen, ${ }^{1,2,6 *}$ Zijian Zhu, ${ }^{1,2 *}$ - Ren Na, ${ }^{1,2,3,4 *}$ Wan Fang, ${ }^{1,2,5,7}$ Wenxia Zhang, ${ }^{1,2}$ Qin Zhou, ${ }^{8}$ Shanbi Zhou, ${ }^{10}$ \\ Han Lei, ${ }^{8}$ Ailong Huang, ${ }^{8}$ Tingmei Chen, ${ }^{8}$ Dongsheng Ni, ${ }^{8,9}$ Yuping Gu, ${ }^{8,9}$ Jianing Liu, ${ }^{8,9}$-Fang Fang, $, 1,2,3,4$ \\ and $\odot$ Yi Rao ${ }^{1,2,5,7}$ \\ ${ }^{1}$ PKU-IDG/McGovern Institute for Brain Research, ${ }^{2}$ Peking-Tsinghua Center for Life Sciences, ${ }^{3}$ School of Psychological and Cognitive Sciences, ${ }^{4}$ Beijing Key \\ Laboratory of Behavior and Mental Health, ${ }^{5}$ Beijing Advanced Innovative Center for Genomics, Peking University, Beijing 100871, China, ${ }^{6} \mathrm{Central}$ \\ Laboratory, the Affiliated Hospital of Nanjing University of Chinese Medicine, Jiangsu Province Hospital of Traditional Chinese Medicine, Nanjing 210029, \\ China, ${ }^{7}$ The Chinese Institute for Brain Research, Beijing 100871, China, ${ }^{8}$ College of Laboratory Medicine, ${ }^{9}$ Division of Molecular Nephrology and Creative \\ Training Center for Undergraduates, MOE Key Laboratory of Medical Diagnostics, Chongqing Medical University, Chongqing 400016, China, and \\ ${ }^{10}$ University-Town Hospital of Chongqing Medical University, Chongqing 401331, China
}

Visual cognition in humans has traditionally been studied with cognitive behavioral methods and brain imaging, but much less with genetic methods. Perceptual rivalry, an important phenomenon in visual cognition, is the spontaneous perceptual alternation that occurs between two distinct interpretations of a physically constant visual stimulus (e.g., binocular rivalry stimuli) or a perceptually ambiguous stimulus (e.g., the Necker cube). The switching rate varies dramatically across individuals and can be voluntarily modulated by observers. Here, we adopted a genomic approach to systematically investigate the genetics underlying binocular rivalry, Necker cube rivalry and voluntary modulation of Necker cube rivalry in young Chinese adults (Homo sapiens, $81 \%$ female, $20 \pm 1$ years old) at multiple levels, including common single nucleotide polymorphism (SNP)-based heritability estimation, SNP-based genome-wide association study (GWAS), gene-based analysis, and pathway analysis. We performed a pilot GWAS in 2441 individuals and replicated it in an independent cohort of 943 individuals. Common SNP-based heritability was estimated to be $25 \%$ for spontaneous perceptual rivalry. SNPs rs184765639 and rs75595941 were associated with voluntary modulation, and imaging data suggested genotypic difference of rs184765639 in the surface area of the left caudal-middle frontal cortex. Additionally, converging evidence from multilevel analyses associated genes such as PRMT1 with perceptual switching rate, and MIR1178 with voluntary modulation strength. In summary, this study discovered specific genetic contributions to perceptual rivalry and its voluntary modulation in human beings. These findings may promote our understanding of psychiatric disorders, as perceptual rivalry is a potential psychiatric biomarker.

Key words: GWAS; heritability; perceptual rivalry; structural MRI; voluntary modulation

\section{Significance Statement}

Perceptual rivalry is an important visual phenomenon in which our perception of a physically constant visual input spontaneously switches between two different states. There are individual variations in perceptual switching rate and voluntary modulation strength. Our genomic analyses reveal several loci associated with these two kinds of variation. Because perceptual rivalry is thought to be relevant to and potentially an endophenotype for psychiatric disorders, these results may help understand not only visual cognition, but also psychiatric disorders.

\section{Introduction}

Visual cognition is traditionally studied in animals with electrophysiology and in humans with behavioral and brain imaging methods. Genomic technologies including microarray and se- quencing provide a powerful approach to study human visual cognition. Here, we chose to investigate perceptual rivalry because it is an intriguing visual cognitive phenomenon known for centuries as well as a potential biomarker for psychiatric disor-
This work was supported by National Natural Science Foundation of China (Projects 31421003 and 31671168 ). We thank Houfeng Zheng, Chen Wu, and Jurg Ott for advice on the manuscript, and Zhangyan Guan and Huizhen Yang for help with DNA preparation.

The authors declare no competing financial interest.

*B.C., Z.Z., and R.N. contributed equally as co-first authors. 
A
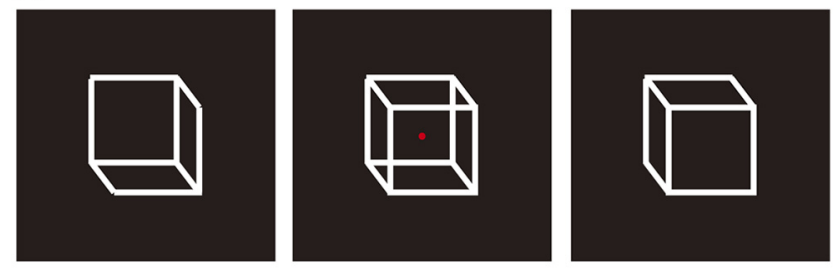

B

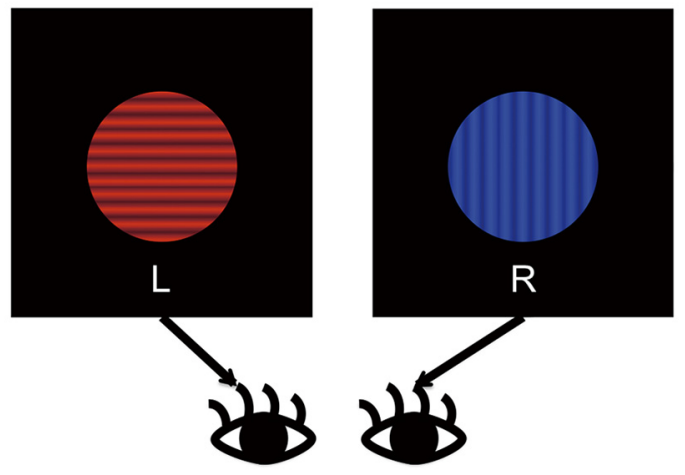

Figure 1. Experimental stimuli. $\boldsymbol{A}$, Necker cube stimulus (middle). It has two interpretations: a cube facing top-left (left) or bottom-right (right). $\boldsymbol{B}$, In the binocular rivalry task, subjects viewed the stimulus through red-blue anaglyph eyeglasses. They received a red horizontal grating in one eye (left, L) and a blue vertical grating in the other eye (right, R).

ders (Ngo et al., 2011). When observing a perceptual rivalry stimulus, our brain oscillates spontaneously between two distinct percepts although the retinal input remains unchanged. Wellstudied examples of perceptual rivalry include the Necker cube (Fig. 1A, middle; Necker, 1832), which can be perceived as either facing top-left (Fig. 1A, left) or bottom-right (Fig. 1A, right), and binocular rivalry, which can be elicited when two eyes receive different sensory inputs (Fig. $1 B$ ). Perceptual rivalry can be topdown influenced: individuals may change their switching rate via voluntary effort (Washburn and Gillette, 1933; Pelton and Solley, 1968; Liebert and Burk, 1985; Strüber and Stadler, 1999; Toppino, 2003; Meng and Tong, 2004; van Ee et al., 2005; Kornmeier et al., 2009; Scocchia et al., 2014). Moreover, individuals with clinical conditions such as bipolar disorder (Miller et al., 2003; Nagamine et al., 2009; Vierck et al., 2013) and autism (Ropar et al., 2003; Wimmer and Doherty, 2010; Allen and Chambers, 2011; Robertson et al., 2013) display different rivalry patterns; slower switching rate in bipolar disorder and longer mixed perceptual states in autism.

The physiological bases for perceptual rivalry and top-down voluntary modulation have been investigated with electrophysiology and imaging methods in monkeys (Leopold and Logothetis, 1996; Xu et al., 2016) and with electroencephalography (Strüber et al., 2001; Kornmeier and Bach, 2004; İsoğlu-Alkac and Strüber, 2006; Mathes et al., 2006; Pitts et al., 2008), magnetoencephalography (Parkkonen et al., 2008), magnetic resonance imaging (MRI; Lumer et al., 1998; Inui et al., 2000; Sterzer and Kleinschmidt, 2007; Watanabe et al., 2014), and brain stimulation (Ngo et al., 2013; Brascamp et al., 2018) in humans. Sponta-

Correspondence should be addressed to either of the following: Fang Fang, School of Psychological and Cognitive Sciences, Peking University, 5 Yiheyuan Road, Beijing, 100871, China, E-mail: ffang@pku.edu.cn; or Yi Rao, PekingTsinghua Center for Life Sciences, Peking University, 5 Yiheyuan Road, Beijing, 100871, China, E-mail:yrao@pku.edu.cn. https://doi.org/10.1523/JNEUROSCl.1970-17.2018

Copyright $@ 2018$ the authors $\quad 0270-6474 / 18 / 389669-11 \$ 15.00 / 0$ neous perceptual alternation may be mediated by brain regions in visual cortex (Meng et al., 2005; Frässle et al., 2014; Ishizu and Zeki, 2014) and frontoparietal networks (Cohen, 1959; Ricci and Blundo, 1990; Meenan and Miller, 1994; Bisiach et al., 1999; Miller et al., 2000; Slotnick and Yantis, 2005; Ge et al., 2007; Fagard et al., 2008; Shen et al., 2009; Sterzer et al., 2009; Kanai et al., 2010; Knapen et al., 2011; Wang et al., 2013; Weilnhammer et al., 2013; Megumi et al., 2015). The premotor and parietal areas, the dorsolateral prefrontal cortex, the anterior cingulate cortex, the putamen and a cortico-striato-thalamo-cortical network may be involved in the voluntary modulation of perceptual rivalry (Windmann et al., 2006; Raz et al., 2007; de Graaf et al., 2011). Perceptual switching rate was positively correlated with gray matter volume in the posterior-superior parietal lobe and the dorsolateral prefrontal cortex, but was negatively correlated with that in visual areas such as V5 and the lateral occipital cortex (Watanabe et al., 2014). It was also positively correlated with cortical thickness of the superior parietal cortex (Kanai et al., 2010). Switching rate can be increased by psychoactive drugs such as caffeine, or decreased by alcohol and sodium amytal (George, 1936). Pharmacological studies have implicated the involvement of dopaminergic (Phillipson and Harris, 1984), GABAergic (van Loon et al., 2013), and serotoninergic systems (Carter et al., 2005a; Nagamine et al., 2008) in perceptual rivalry.

Perceptual switching rate is highly variable across individuals (Aafjes et al., 1966; Wang et al., 2014), but is quite stable for an individual (George, 1936; Pettigrew and Miller, 1998; Enoksson, 1963; Miller et al., 2010). Voluntary modulation strength also varies dramatically from person to person (Scocchia et al., 2014). Previous studies have attributed individual differences in switching rate to psychological factors such as psychiatric abnormalities (Hunt and Guilford, 1933), anxiety state (Nagamine et al., 2007; Van de Cruys et al., 2013), and mindfulness (Carter et al., 2005b), and to large-scale brain activity dynamics (Watanabe et al., 2014) and brain structures (Kanai et al., 2010). Using twin models, moderate heritability was found for several types of perceptual rivalry (Miller et al., 2010; Shannon et al., 2011; Wang et al., 2014).

In this study, we first analyzed the common single nucleotide polymorphism (SNP) heritability of perceptual rivalry and voluntary modulation with the GCTA program (Yang et al., 2011). We then adopted a classic two-stage discovery/replication genome-wide association study (GWAS) strategy at the levels of SNP, gene, and pathway, to dissect the molecular genetics of these phenotypes. At the first stage (i.e., discovery stage), we performed a pilot GWAS with $>2400$ individuals, aiming to discover a small set of SNPs showing highly suggestive significance in association with phenotypes of interest. At the second stage (i.e., replication stage), we conducted a replication study in another independent cohort to confirm the associations of the candidates discovered at the first stage. In addition, association tests at the levels of gene and pathway and brain scanning with structural MRI were conducted. The association results would be strengthened if brain correlates of these variants could be found. Multilevel analyses provide a broad view on how and to what extent genetic components contribute to perceptual rivalry and voluntary modulation. As already mentioned, this work could improve understanding of perceptual rivalry in psychiatric disorders, but it could also stimulate further research into cognitive functions such as attention and consciousness (Blake and Logothetis, 2002) because perceptual rivalry has been a key experimental paradigm for studying such functions. 


\section{Materials and Methods}

\section{Participants}

The GWAS discovery and replication cohorts consisted of college students recruited from the Chongqing Medical University, with a mean age of 20 years $(\mathrm{SD}=1), 81 \%$ female, $94 \%$ Han. The psychiatric history and medication history were screened by medical examination at the time of college entrance and by self-reported questionnaires just before the current study. None of the subjects reported having psychiatric disorders, having a history of brain injuries, having a first-degree relative with psychiatric disorders, having vision disorders, or currently taking medication. Visual acuity for each subject was measured with the software program FrACT v3.8.2, which is based on the Freiburg Vision Test (Bach, 1996). A Landolt-C, as an opto-type, was presented at the center of the screen, $1.4 \mathrm{~m}$ away from subjects. Subjects were asked to make an eightalternative forced-choice judgment on the orientation of the Landolt-Cs. The program estimated acuity threshold using a method called Best Parameter Estimation by Sequential Testing. All subjects had normal or corrected-to-normal visual acuity. No significant difference in ethnicity or place of origin between the discovery and replication cohorts was found (Pearson's $\chi^{2}$ test). Data for the discovery and replication cohorts were collected in the autumn of 2014 and the spring of 2015, respectively. Written informed consents were collected before experiments. The human subject review committee in the School of Psychological and Cognitive Sciences at the Peking University approved the experimental procedures.

\section{Experimental design}

In the binocular rivalry experiment, the stimulus was presented on a dark background and consisted of two overlapped sinusoidal gratings (orientation: horizontal and vertical; color: red and blue; diameter: $1.5^{\circ}$ of visual angle; spatial frequency: 5 cycles $/^{\circ}$; phase: random; contrast: 0.9 ). The two gratings drifted simultaneously in vertical or horizontal directions at a speed of $1 \%$ s (Fig. 1B). A purple dot at the center of the gratings served as a fixation point. Subjects viewed the stimulus through red-blue anaglyph eyeglasses, with the red horizontal grating presented to their left eye and the blue vertical grating presented to their right eye. Since the two small gratings presented in the fovea were dramatically different in color, orientation, and moving direction, participants experienced clear-cut binocular rivalry with little mixed percept; their percept alternated between a blue leftward-moving grating and a red upward-moving grating. For the Necker cube experiment, a cube composed of 12 white bars was presented on a dark background, subtending $1^{\circ} \times 1^{\circ}$ of visual angle. A red dot at the center of the cube served as a fixation point. To minimize eye movement (Ellis and Stark, 1978), subjects were requested to fixate the central dot throughout the experiment.

All stimuli were presented on a Lenovo LCD monitor with a spatial resolution of $1024 \times 768$ and a refresh rate of $60 \mathrm{~Hz}$. Luminance was measured with a MINOLTACS-100A Chroma Meter (Konica Minolta Sensing Americas). The luminance levels of the background, the gratings, and the Necker cube were $0 \sim 1 \mathrm{~cd} / \mathrm{m}^{2}, 46 \mathrm{~cd} / \mathrm{m}^{2}$ (mean luminance), and $200 \mathrm{~cd} / \mathrm{m}^{2}$, respectively. The stimuli were generated and controlled using MATLAB and Psychtoolbox (Brainard, 1997).

At the beginning, subjects were informed about the reversibility of the stimuli and two possible perceptual states (Fig. 1). After they were able to perceive both states, they took $1 \mathrm{~min}$ training. Subjects were instructed to press one key when they perceived the red horizontal grating (or the cube facing top-left) and the other key for the blue vertical grating (or the cube facing bottom-right). Subjects were notified about the possibility of mixed percept during rivalry and they were instructed to classify mixed percept into either state based on which state covered the majority of the stimulus field. Subjects were asked to report occurrence of persistent mixed percept after each trial. Eleven subjects who reported persistent mixed percept were excluded from the experiment. For the binocular rivalry experiment, subjects were instructed to view the stimulus naturally without any voluntary effort. The experiment consisted of eight trials, each lasting $1 \mathrm{~min}$, with a 1-3 min (self-paced) break in between. Subjects decided when to start the next trial by pressing a "start" button that would appear on the screen 1 min after the end of a trial. For the Necker cube experiment, there were two conditions: the spontaneous switch condition and the voluntary modulation condition. In the former condition, subjects viewed the stimulus passively without any voluntary effort. In the latter condition, subjects were asked to do their best to increase their perceptual switching rate. The spontaneous switch condition was followed by the voluntary modulation condition. Each condition consisted of five trials, each lasting $1 \mathrm{~min}$, with a $1-3 \mathrm{~min}$ break in between. Perceptual switching rate was measured as the number of perceptual switches per minute, averaged across all the trials in the spontaneous switch condition ( $8 / 5$ trials for binocular/Necker cube rivalry). The voluntary modulation strength was calculated as (the switching rate in the voluntary modulation condition- the switching rate in the spontaneous switch condition)/the switching rate in the spontaneous switch condition. We did not ask subjects to voluntarily increase their perceptual switching rate in the binocular rivalry experiment. This is because, in a pilot study, we found such voluntary modulation had little effect on binocular rivalry, which is consistent with previous findings (Meng and Tong, 2004). In the voluntary modulation condition for the Necker cube, subjects were asked to speed up, rather than slow down, their perceptual switching rate. We chose this option because we were concerned that instructing subjects to slow down switching rate might be confounded by factors such as simply diverting attention from the task (but see Discussion).

\section{Genotyping and quality control}

Discovery cohort. DNA was extracted from peripheral blood of participants using the QuickGene whole-blood genome DNA extract system (Kurabo Industries), and was genotyped for 894,517 common SNPs using the HumanOmniZhongHua-8 Beadchip v1.2 (Illumina). Common quality control parameters were applied to the genotype data and retained 830,937 SNPs. SNPs were included in the analysis if they met the following criteria: call rate $>0.95$, minor allele frequency (MAF) $>0.01$, and Hardy-Weinberg equilibrium test with $p>10^{-4}$. Differences in allele frequencies between the discovery and the replication cohorts were examined using paired sample $t$ test, and no significant deviation was observed (MAF of the replication cohort were all within $2 \mathrm{SD}$ from the mean MAF of the discovery cohort). Individuals with genotyping call rate $<0.95$ were excluded. Potential duplicates or close relatives were examined by calculating an identity-by-state (IBS) similarity matrix implemented in PLINK (Purcell et al., 2007), and none was excluded due to IBS distance $\leq 0.75$ (corresponding to siblings). Individuals with extreme phenotypes outside $4 \mathrm{SD}$ from the population mean were taken as phenotypic outliers and removed from subsequent analyses (Table 1-1, available at https://doi.org/10.1523/JNEUROSCI.1970-17.2018.t1-1). Population stratification within this cohort was examined with EIGENSTRAT (Price et al., 2006) via principal component analysis (PCA). Genetic outliers were detected and excluded automatically under a default mode [the maximum number of outlier removal iterations was 5; an individual outside $6 \mathrm{SD}$ from the population mean in terms of genetic principal component (PC) was removed as an outlier]. Approximately $1.5 \%$ of participants in the discovery cohort were excluded as outliers (phenotypic and genetic). The sex ratios of the outliers were similar to those of the full sample. After outlier removal, the genetic backgrounds of the ethnic groups in the remaining populations did not significantly differ from that of the Han individuals. A total of 2441 (2097 for binocular rivalry, 1880 for Necker cube rivalry, 1876 for voluntary modulation strength) subjects with both phenotypic and genotypic data available were included in the final analysis (Table 1-1, available at https://doi.org/10.1523/JNEUROSCI.1970-17.2018.t1-1).

Replication cohort. The replication cohort was a new sample genotyped on the HumanOmniZhongHua-8 Beadchip v1.1. The same quality control protocol as that at the discovery stage was applied, resulting in a final dataset of 830,937 SNPs genotyped in a homogenous sample of 943 individuals ( 870 for binocular rivalry, 748 for Necker cube rivalry, 744 for voluntary modulation strength), with $3.5 \%$ of the replication cohort identified as outliers and discarded (Table 1-1, available at https:// doi.org/10.1523/JNEUROSCI.1970-17.2018.t1-1).

\section{Statistical analysis}

Heritability estimation. We performed a restricted maximum likelihood (REML) analysis by GCTA v1.24 (Yang et al., 2011) to estimate the phe- 
notypic variance explained by all common SNPs (SNP heritability). This method measures the variance in the trait that is attributable to the genetic difference across the population. The discovery and replication cohorts were combined into one sample. We estimated the genetic relationship matrix (GRM) using all autosomal markers that were genotyped and checked for quality control as described above (altogether 830,937). One individual in each pair was excluded if the estimated genetic relatedness of that pair was $>0.025$ (Yang et al., 2010). Twenty-four individuals were excluded and 2935 remained. We adopted the GRM-REML (GREML) method to estimate the variance explained by common SNPs, with the first 20 eigenvectors from PCA included as covariates. We used an additive model because dominant effects accounted for very little of the total genetic effects when SNP heritability analysis assumed a full model. We used the online GCTA-GREML Power Calculator (Visscher et al., 2014) to calculate the statistical power. We estimated genetic correlations for binocular rivalry and Necker cube rivalry by bivariate GREML implemented in GCTA.

We explored the genetic correlations between the measured phenotypes in our Chinese population and five psychiatric disorders (bipolar disorder, major depression, schizophrenia, autism spectrum disorder, and attention deficit hyperactivity disorder) in a Caucasian population by linkage disequilibrium (LD) score regression analysis (Bulik-Sullivan et al., 2015) via the web-based LD Hub (Zheng et al., 2017). Summary GWAS data from the discovery cohort were used as inputs. Significance threshold was set at $p=0.0033$.

Imputation. Genotypes were pre-phased into haplotypes with SHAPEIT (Delaneau et al., 2012; Howie et al., 2012). Imputation was then performed using IMPUTE v2.3.1 (Howie et al., 2009) based on 1000 Genomes haplotype data [Phase I integrated variant set release (SHAPEIT2) in NCBI build 37/UCSC hg19] with 36,820,992 SNPs, 1384,273 short biallelic indels and 14,017 structural variations. Quality control retained those variants with information (INFO) $>0.4$ and MAF $>0.01$ for subsequent analyses, which were $7,992,300 ; 7,990,224$; and $7,989,184$ SNPs for binocular rivalry, Necker cube rivalry, and voluntary modulation strength, respectively.

GWAS. Perceptual switching rates were taken as quantitative traits. The first 10 PCs estimated by EIGENSTRAT were tested for phenotypic associations using linear regression. Effects of demographic factors (sex, age, ethnicity, and birthplace) were also tested using linear regression with phenotypes. None of those factors showed association with $p<0.05$ when all factors were included as independent variables or only a particular factor was included as an independent variable. Thus, no covariate was included in subsequent association tests. Based on the Score Method in the Frequentist Test framework, association tests of imputed SNPs were performed with SNPTEST v2.5 (Marchini et al., 2007), assuming an additive model. The full set of $p$ values that emerged from association analyses was loaded and visualized in Haploview v4.2 (Barrett et al., 2005) to generate Manhattan plots. Basic statistical analyses were performed, the genomic inflation factor $\lambda$ was calculated, and quantilequantile (Q-Q) plots for observed versus expected $p$ values were generated, all by R v3.2.1 (https://www.R-project.org). Genome-wide significance threshold was set at $(5 / 3) \times 10^{-8}$. Regional association plots were drawn for two mega-bases around top candidate SNPs from the discovery GWAS by the web-based LocusZoom (http://locuszoom. sph.umich.edu/locuszoom), only with variants that passed quality control. Quanto v1.2 was used for power calculation (Gauderman and Morrison, 2006). The power of this study to discover those genome-wide significant SNPs was $>0.85$ for Necker cube rivalry and its voluntary modulation strength (with $R^{2}>0.005$ and MAF $>0.01$ ), and $0.10 \sim$ 0.33 for binocular rivalry (with $R^{2}>0.0002$ and MAF $>0.01$ ).

Candidate selection and replication. Genome-wide significant SNPs at the discovery stage were selected as candidates for follow-up replication. Genotypes of the selected SNPs were obtained from the replication cohort and were tested by SNPTEST v2.5 under a general linear regression model. Candidate SNPs were functionally annotated via online tools SNPnexus (http://snp-nexus.org) and 3DSNP (http://cbportal.org/ $3 \mathrm{dsnp} /$ ). We examined the following items in SNPnexus: copy number variation, Ensemble-Regulatory Build, Roadmap Epigenomics, ENCODE, genetic association of complex diseases and disorders (GAD), and non- coding scoring method including combined annotation-dependent depletion, fitness consequences of functional annotation, unsupervised spectral approach integrating functional annotation, functional analysis through hidden Markov models, genome-wide annotation of variants, chromatin effects of sequence alterations, regulatory Mendelian mutation, and FunSeq2. All the genomic positions reported in the main text were based on the $h g 38$ unless otherwise specified.

Gene-based analysis and pathway analysis. Gene-based association tests and pathway analyses were performed by VEGAS2 (Liu et al., 2010; Mishra and Macgregor, 2015, 2017). Approximately 21,135 genes were tested. SNP to gene mapping was based on the $h g 19$. VEGAS2 used SNPs within genes or in $>0.8 r^{2}$ LD with a SNP in genes, from Southern Han Chinese in 1000 Genomes-ASIAN. All autosomal chromosomes were taken into consideration, while no allele frequency difference between males and females was assumed during LD calculation. Pathway databases included gene ontology (GO), KEGG, REACTOME, BIOCARTA, and PANTHER (9734 pathways in total). Genome-wide significance threshold was set at familywise error rate $($ FWER $)=0.05$, which was $0.05 /(21,135 \times 3)=7.9 \times 10^{-7}$ for gene-based analysis and $0.05 /$ $(9734 \times 3)=1.71 \times 10^{-6}$ for pathway analysis. We selected the genes and pathways with uncorrected $p<0.05$ as candidates for further tests at the replication stage. The significance thresholds for replication were $0.05 /$ the total number of candidates.

Functional validation by structural MRI. To test the genotypic difference in brain anatomical features, we performed structural brain imaging on a 3 Tesla Discovery MR750 whole-body MAGNETOM scanner (GE Healthcare) in the MRI Center at Peking University. Head movement was restricted with padding. Three-dimensional T1-weighted highresolution anatomical data were acquired using a 32-channel head coil with the following parameters: three-dimensional magnetizationprepared rapid gradient-echo sequence, repetition time: $6.6 \mathrm{~s}$, echo time: $2.92 \mathrm{~ms}$, field-of-view: $256 \times 256 \mathrm{~mm}^{2}$, matrix: $256 \times 256$, slice thickness: $1 \mathrm{~mm}$, number of slices: 192, gap: $0 \mathrm{~mm}$, flip angle: $12^{\circ}$, voxel size: $1 \times 1 \times 1 \mathrm{~mm}^{3}$. Data were collected from 125 subjects and they were genotyped on candidate SNPs. The structural MRI data were analyzed using default procedures implemented in the FreeSurfer software package (http://freesurfer-software.org). Based on previous studies (Kanai et al., 2010; Watanabe et al., 2014), we took the following FreeSurfer-defined brain regions as the regions-of-interest for subsequent genotype-structure association tests: the superior parietal gyrus and parieto-occipital sulcus in the Destrieux Atlas for binocular rivalry and Necker cube rivalry, the caudal and rostral middle frontal cortex in the DKT Atlas for voluntary modulation strength. For each region-of-interest, left and right hemispheres were considered separately, and three anatomical features-surface area, volume, and cortex thickness-were considered. Therefore, for each candidate SNP, 12 brain structural features were used as morphometric phenotypes. For each tested SNP and each brain morphometric feature, a one-way analysis of variance was performed, with the brain morphometric phenotype as a dependent variable and the SNP genotype as an independent variable. Significance threshold was set at FWER $=0.05$, which was $0.05 /(12 \times$ the number of tested SNPs).

\section{Results}

\section{Behavioral results}

There were two subject samples: the discovery sample and the replication sample (Table 1 ). In the spontaneous switch condition [hereafter binocular rivalry (BR) and Necker cube rivalry (NC), respectively], perceptual switches per minute were 29.69 \pm 0.18 for BR and $7.76 \pm 0.06$ for $\mathrm{NC}$ (mean \pm SEM; Table 1 ). The phenotypic correlation between $\mathrm{BR}$ and $\mathrm{NC}$ perceptual switching rates was 0.19 (Spearman's rank correlation, $p<0.001$ ). Voluntary modulation was able to significantly increase the switching rate in NC by $53.77 \pm 1.66 \%$ (Wilcoxon signed rank test: $p<$ 0.001 ; Table 1 ). We adopted the percentage increase in perceptual switching rate due to voluntary effort (hereafter denoted as VOLUNTARY) to quantify the influence of top-down control. 
Table 1. Summary of phenotypes in all cohorts

\begin{tabular}{|c|c|c|c|c|c|}
\hline & Sex, male $\%$ & Age, $y$ & $\mathrm{BR}$ & NC & VOLUNTARY \\
\hline \multicolumn{6}{|l|}{ Discovery cohort } \\
\hline$N$ & & 2441 & 2097 & 1880 & 1876 \\
\hline Range & & $16 \sim 25$ & $0.63 \sim 72.38$ & $1.30 \sim 21.60$ & $-0.90 \sim 4.68$ \\
\hline Mean \pm SD & 21.2 & $20 \pm 1$ & $29.73 \pm 9.71$ & $7.74 \pm 3.04$ & $0.54 \pm 0.78$ \\
\hline \multicolumn{6}{|c|}{ Replication cohort } \\
\hline$N$ & & 943 & 870 & 748 & 744 \\
\hline Range & & $18 \sim 26$ & $0.88 \sim 61.88$ & $0 \sim 63.50$ & $-6.00 \sim 24.90$ \\
\hline Mean \pm SD & 12.4 & $21 \pm 1$ & $29.61 \pm 9.15$ & $7.72 \pm 2.79$ & $0.53 \pm 0.75$ \\
\hline
\end{tabular}

All data are untransformed raw phenotypic scores. BR, binocular rivalry; NC, Necker cube rivalry; VOLUNTARY, voluntary modulation strength; $\mathrm{N}$, number of subjects. For more details on studied cohorts, see Table 1-1 (available at https://doi.org/10.1523/JNEUROSCI.1970-17.2018.t1-1).

\section{Heritability estimation}

We adopted the GREML method to estimate SNP heritability of these perceptual rivalry traits, through quantifying the proportion of phenotypic variance explained by all genotyped autosomal SNPs. Results showed that $\sim 25 \%(\mathrm{SE}=13 \%, p=0.026)$ of the phenotypic variance in BR could be explained by all genotyped common SNPs, whereas that percentage for NC was $23 \%$ $(\mathrm{SE}=16 \%, p=0.069$; Table 2$)$. The genetic correlation between $\mathrm{BR}$ and $\mathrm{NC}$ was $0.24(\mathrm{SE}=0.46)$. This $\mathrm{SNP}$-based analysis suggests a moderate SNP heritability for spontaneous perceptual rivalry. BR and NC might share partial genetic basis. No significant common SNP heritability estimate was found for VOLUNTARY (Table 2). LD regression did not find any significant genetic correlation with the tested psychiatric disorders (Table 2-1, available at https://doi. org/10.1523/JNEUROSCI.1970-17.2018.t2-1).

\section{GWAS of single-marker association}

Classic GWAS was first performed in the discovery cohort on the imputed markers after quality control. The genomic inflation factor $\lambda$ was 1.00 for all association tests. Thus, the significance reported herein was not affected by population stratification. The overall association results across the whole genome are shown in Manhattan plots (Fig. 2). One, 15, and 92 SNPs reached genomewide significance after multiple-testing correction $(p<1.67 \times$ $10^{-8}$ ) for BR, NC, and VOLUNTARY, respectively (Fig. 2; Table 3-1, available at https://doi.org/10.1523/JNEUROSCI.1970-17. 2018.t3-1). The number of markers with genome-wide significance was much larger than that expected by chance, as illustrated by Q-Q plots (Fig. 3). The only genomic significant SNP for BR was rs11742135 (chr5:121646077A >C; Fig. 4A), but its association signal in the replication cohort was not significant $(p=0.6)$. For NC, one genome-wide significant SNP, rs190906337 (chr2: $211072859 \mathrm{~T}>\mathrm{C}$ ), reached an uncorrected $p=0.018$ at the replication stage (Fig. 4B). Two SNPs for VOLUNTARY, namely, rs75595941 (chr6:68772523T $>$ C; Fig. 4C) and rs184765639 (chr4:79651292G >A; Fig. 4D), displayed significant association signals after multiple-testing correction $\left(p<4.63 \times 10^{-4}\right)$ at the replication stage (Table 3 ). The effect directions for these markers in the replication cohort were consistent with those in the discovery cohort. rs 184765639 is predicted to be highly functional (by several noncoding scoring methods; Table 3-2, available at https:// doi.org/10.1523/JNEUROSCI.1970-17.2018.t3-2) and associated with some complex metabolic or hematological diseases (from $\mathrm{GAD}$ ). Another associated SNP rs75595941, which is located in one intron of $A D G R B 3$ (Adhesion G-protein-coupled receptor B3), has been associated with various complex diseases including narcolepsy (from GAD). Functional predictions of these top associated variants are listed in Table 3-2 (available at https://doi.org/10.1523/ JNEUROSCI.1970-17.2018.t3-2).

\section{Gene-based analysis and pathway analysis}

Gene-based analysis integrated weak SNP signals into a gene and thus increased signal-to-noise ratio in a genomic association study. We used a gene-based software program VEGAS2. The gene encoding an olfactory receptor, OR11A1, reached an uncorrected $p=2 \times 10^{-6}$ (but did not pass the genome-wide significance level of $7.9 \times 10^{-7}$ ) at the discovery stage for BR. Among these candidate genes with uncorrected $p<0.05$ (Table 3-3, available at https://doi.org/10.1523/JNEUROSCI.1970-17.2018. t3-3), OR1L6 (encoding an olfactory receptor) reached corrected significance for NC [uncorrected $p=1.10 \times 10^{-5}<(0.05 /$ $\left.3231)=1.55 \times 10^{-5}\right]$, whereas MIR1178 was significant for VOLUNTARY (uncorrected $p=1.00 \times 10^{-6}<1.55 \times 10^{-5}$ ) in the replication cohort.

We further performed pathway analysis to explore potential biological pathways involved in perceptual rivalry. No pathway was significant after multiple-testing correction at the discovery stage ( significance threshold $p=1.71 \times 10^{-6}$ ), and none of the selected pathways (Table 3-4, available at https://doi.org/ 10.1523/JNEUROSCI.1970-17.2018.t3-4) could be replicated ( significance threshold $p=0.05 / 1936=2.58 \times 10^{-5}$ ). Two pathways, GO:0042992 (negative regulation of transcription factor import into nucleus) and GO:1901533 (negative regulation of hematopoietic progenitor cell differentiation), were shared by BR and $\mathrm{NC}$ with uncorrected $p<0.05$ at the discovery stage and also showed uncorrected $p<0.05$ for either BR or NC at the replication stage, suggesting their important role in spontaneous perceptual rivalry. It is of note that PRMT1 (protein arginine methyltransferase 1) from pathway GO:1901533 was revealed with uncorrected $p<0.05$ at the gene level for both BR and $\mathrm{NC}$ at the discovery stage (Table 3-5, available at https://doi.org/10. 1523/JNEUROSCI.1970-17.2018.t3-5). The top associated gene MIR1178 was involved in a candidate pathway, G13_Signaling Pathway $\left(p_{\text {discovery }}=0.009, p_{\text {replication }}=0.001\right.$, without correction $)$.

\section{Functional consequences revealed by brain anatomy}

The two successfully replicated SNPs (association signals with FWER $<0.05$ at both the discovery and the replication stages) were tested for associations with brain anatomical features of interest by ANOVA, aiming for functional validation (Table 3-6, available at https://doi.org/10.1523/JNEUROSCI.1970-17.2018. t3-6). Because 24 tests in total were conducted, the corrected significance threshold was $p=0.002$. There was difference (uncorrected $p=0.04$ ) between the two rs 184765639 genotypes (G/A and G/G) in the surface area of the left caudal middle frontal cortex (Table 3-6, available at https://doi.org/10.1523/JNEUROSCI.1970-17.2018.t36). However, this difference was not significant after multipletesting correction. This result suggests potential involvement of rs184765639 in the top-down modulation of perceptual rivalry. Furthermore, rs184765639 was significantly associated with voluntary modulation behavioral score with an uncorrected $p=0.041$ (note that only one SNP was tested for association with the behavioral score, VOLUNTARY; thus, this $p$ value is significant (Table 3-6, available at https://doi.org/10.1523/JNEUROSCI.1970-17.2018. t3-6).

\section{Discussion}

This study performed systematic genomic analyses at multiple levels to investigate an important phenomenon in human visual cognition, perceptual rivalry, and its voluntary modulation. Results from this study suggest several genes implicated in perceptual 
Table 2. Estimations of heritability explained by all autosomal SNPs

\begin{tabular}{llllll}
\hline Phenotype & $\sigma_{\mathrm{a}}^{2}(\mathrm{SE})$ & $\sigma_{\mathrm{e}}^{2}(\mathrm{SE})$ & $\sigma_{\mathrm{p}}^{2}(\mathrm{SE})$ & $R(\mathrm{SE})$ & $P$ \\
\hline BR & $23.76(12.67)$ & $70.42(12.60)$ & $94.18(2.47)$ & $0.252(0.134)^{*}$ & 0.026 \\
NC & $2.06(1.39)$ & $6.84(1.39)$ & $8.90(0.25)$ & $0.231(0.156)$ & 0.069 \\
VOLUNTARY & $0.00(0.092)$ & $0.588(0.092)$ & $0.588(0.016)$ & $0.000(0.156)$ & 2935 \\
\hline
\end{tabular}

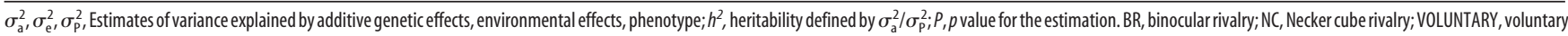
modulation strength. ${ }^{*} p<0.05$. For genetic correlations, see Table 2-1 (available at https://doi.org/10.1523/NNEUROSCI.1970-17.2018.t2-1).

A

BR

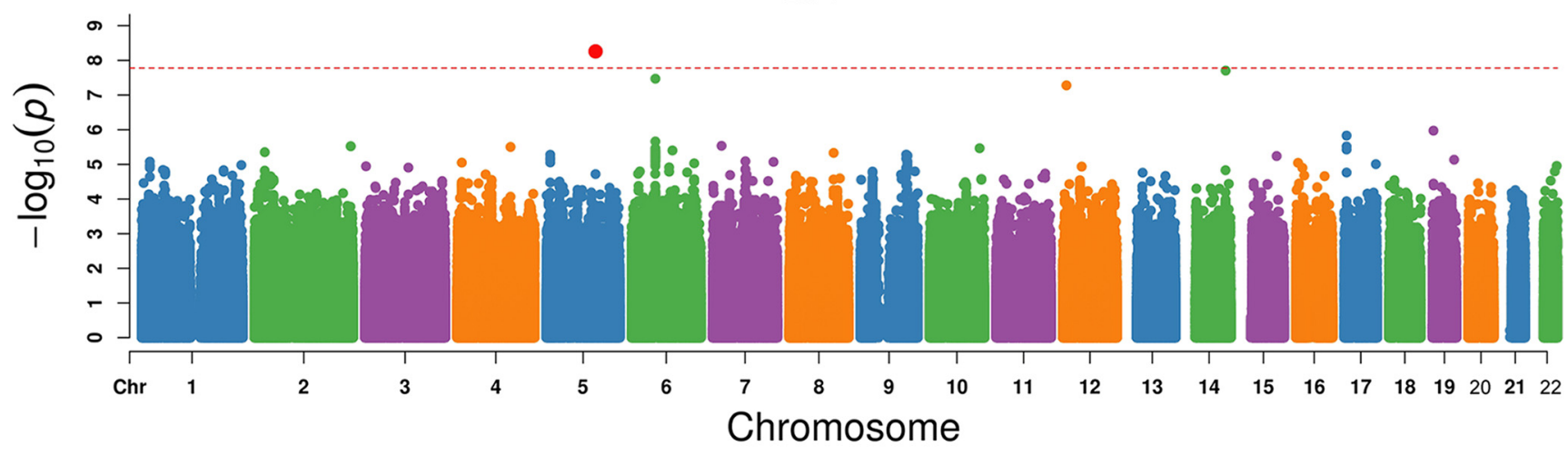

B

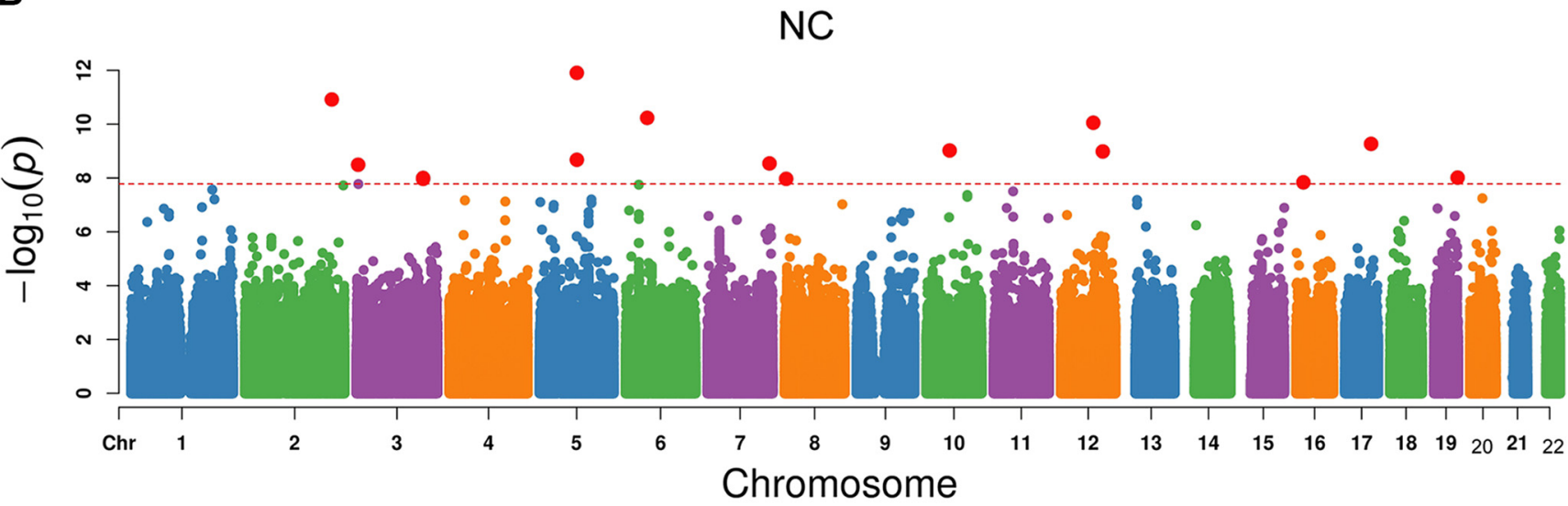

C

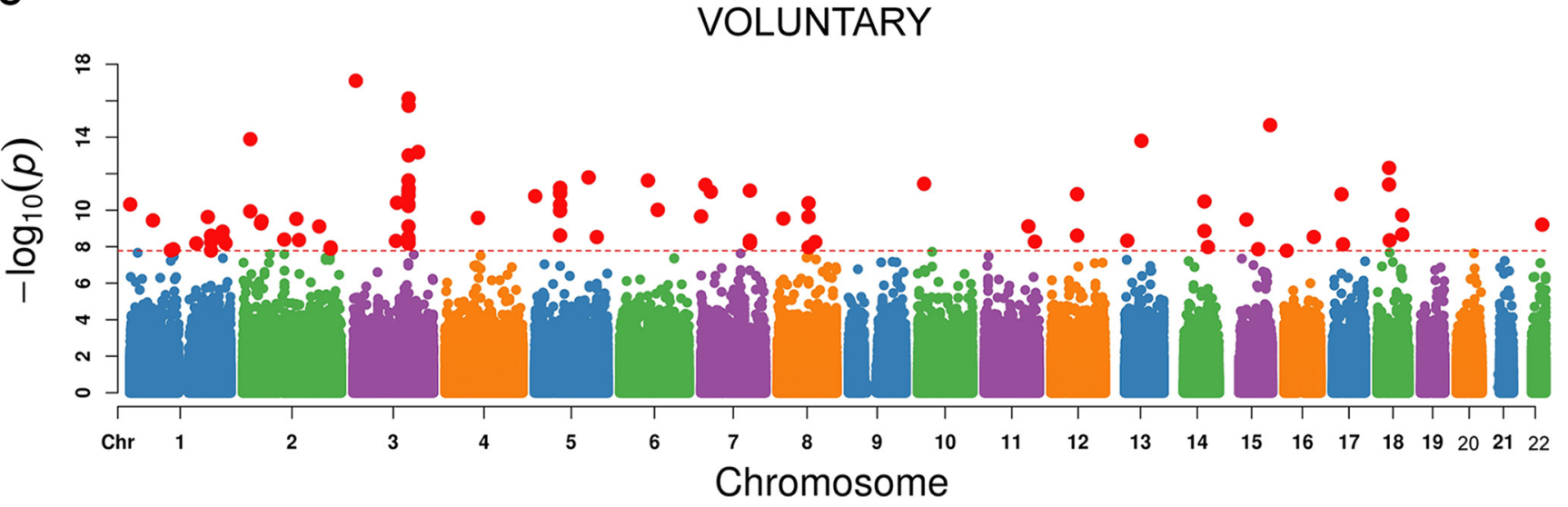

Figure 2. Manhattan plots of genome-wide association study (GWAS) results at the discovery stage. GWAS results $\left[-\log _{10}(p\right.$ value)] are shown in chromosomal order for individually genotyped quality-control-positive single nucleotide polymorphisms (SNPs) that were tested for linear regression with $(\boldsymbol{A})$ perceptual switching rate in the binocular rivalry task (BR), $(\boldsymbol{B})$ spontaneous perceptual switching rate with the Necker cube rivalry (NC), and ( $C$ ) voluntary modulation strength (VOLUNTARY) in the discovery cohort. Results were based on an additive genetic model. Each dot represents one SNP. The red dotted line indicates the genome-wide significance level $\left(1.67 \times 10^{-8}\right)$. Genome-wide significant SNPs are shown as enlarged red dots. Chromosomes are shown in different colors for clarity. 
A

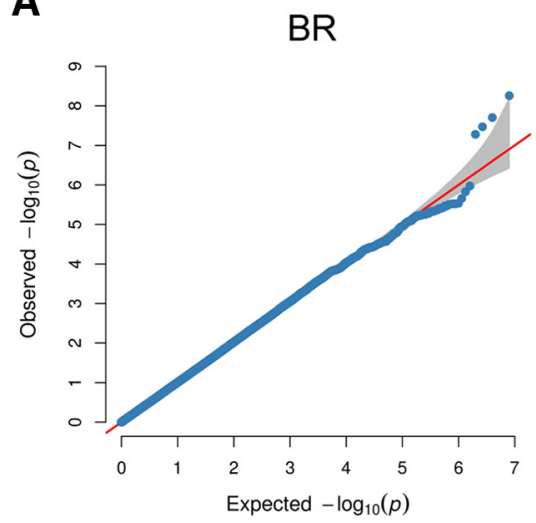

B

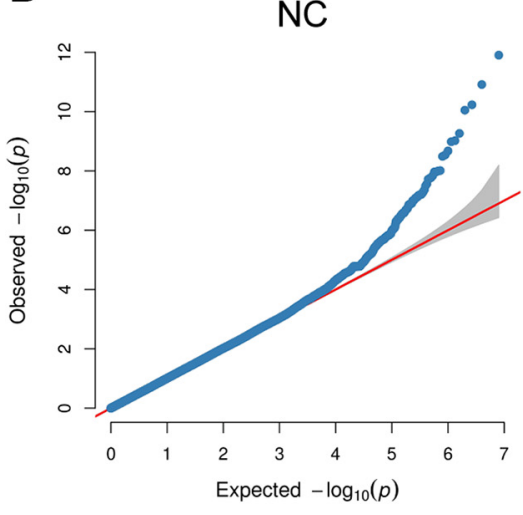

C

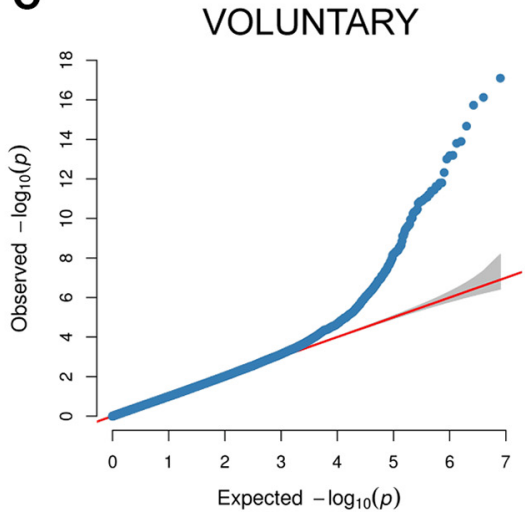

Figure 3. Quantile-quantile plots of genome-wide association study (GWAS) results at the discovery stage. Observed $p$ values relative to expected $p$ values are plotted for (A) perceptual switching rate in the binocular rivalry task (BR), (B) spontaneous perceptual switching rate for the Necker cube rivalry (NC), and (C) voluntary modulation strength (VOLUNTARY), based on $p$ values calculated using linear regression and with significant principal components included as covariates. Each blue dot represents one SNP. The red line indicates the null hypothesis of no association. The gray areas indicate $95 \%$ confidence intervals for the no association line.
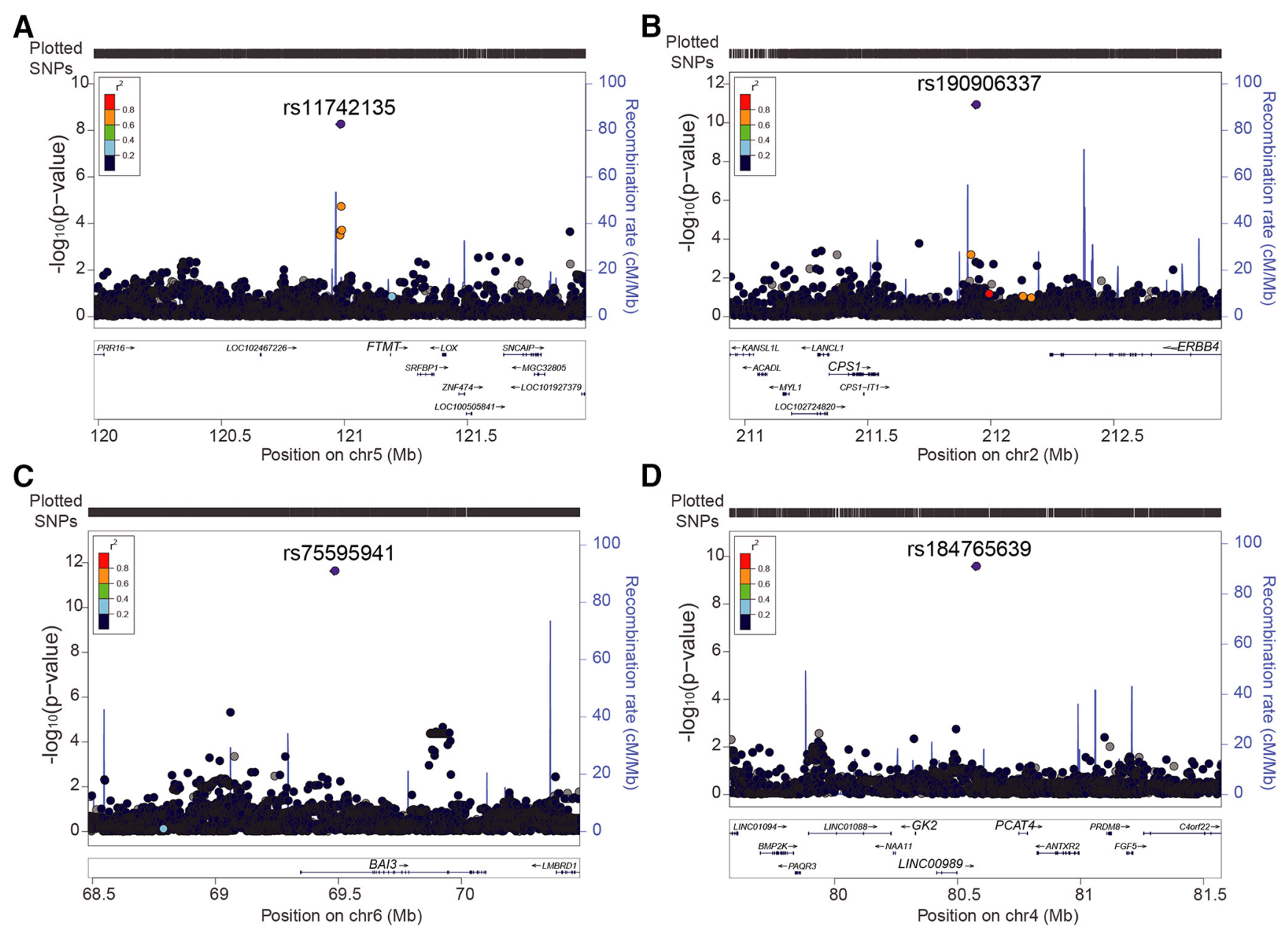

D

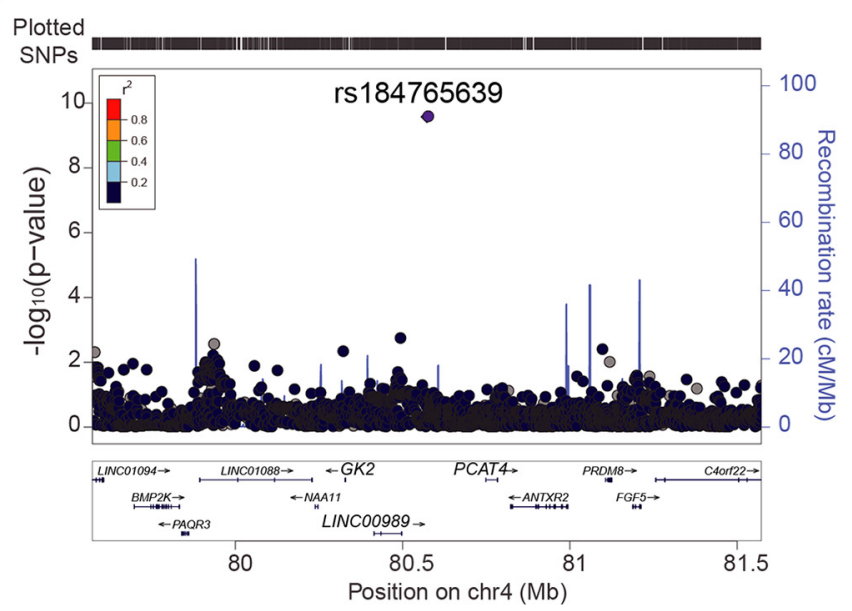

Figure 4. Regional association plot for top associated loci. $\boldsymbol{A}$, The genome-wide significant single nucleotide polymorphism (SNP) at the discovery stage for binocular rivalry (BR), rs11742135. $\boldsymbol{B}$, The SNP with genome-wide significance at the discovery stage and $p<0.05$ at the replication stage for Necker cube rivalry (NC), rs190906337. C, One replicated SNP for voluntary modulation strength (VOLUNTARY), rs75595941. D, One replicated SNP for VOLUNTARY, rs 184765639 . Imputed genotypes from the discovery sample were considered for association tests. Genome build is hg19/1000 Genomes Nov 2014 ASN. Figures are plotted using the web-based LocusZoom program. Each dot represents one SNP.

rivalry and voluntary modulation of rivalry, and demonstrate that modern genomics, in addition to behavioral, electrophysiological, brain imaging, and brain stimulation methods, is an important new approach for studying human cognitive functions. We have performed genomic analyses at four levels: (1) SNP heritability estimation from all SNPs across the genome, (2) SNPbased GWAS, (3) gene-based analysis, and (4) pathway analysis. In addition, we performed a genotypic differential analysis in the phenotype-related brain regions based on structural MRI data, which suggested a role of the SNPs identified from genomic anal- 
Table 3. GWAS results of replicated loci

\begin{tabular}{|c|c|c|c|c|c|c|c|}
\hline \multirow[b]{2}{*}{ SNP } & \multirow[b]{2}{*}{ Position } & \multirow[b]{2}{*}{ Allele } & \multirow[b]{2}{*}{ Gene } & \multicolumn{2}{|l|}{ Discovery } & \multicolumn{2}{|l|}{ Replication } \\
\hline & & & & $\beta(\mathrm{SE})$ & $P$ & $\beta(\mathrm{SE})$ & $P$ \\
\hline rs 184765639 & chr4: 80572446 & $\mathrm{G} / \mathrm{A}$ & LOC105377301 & $2.26(0.36)$ & $2.6 \mathrm{E}-10$ & $3.36(0.33)$ & $7.9 \mathrm{E}-11$ \\
\hline
\end{tabular}

Position, Genomic positions in the form of chromosome: basepair, based on $h g 19$; Allele, major allele/ minor allele; Gene, nearest genes within $30 \mathrm{~kb} ; \beta$ (SE), effect parameter (SE); $P$, uncorrected $p$ value. The sample size for the discovery cohort was 1876. The tested phenotype was voluntary modulation strength. See Table 3-1 (available at https://doi.org/10.1523/JNEUROSCI.1970-17.2018.t3-1) for other GWAS candidates, Table 3-2 (available at https://doi.org/10.1523/ JNEUROSCI.1970-17.2018.t3-2) for functional annotations for candidate SNPs, Table 3-3 (available at https://doi.org/10.1523/JNEUROSCl.1970-17.2018.t3-3) for association results by gene-based analysis, Table 3-4 (available at https://doi.org/10.1523/JNEUROSCI.1970-17.2018.t3-4) for pathway analysis results, Table 3-5 (available at https://doi.org/10.1523/JNEUROSCI.1970-17.2018.t3-5) for genes shared by the two types of rivalry, and Table 3-6 (available at https://doi.org/10.1523/JNEUROSCI.1970-17.2018.t3-6) for functional validation of the two variants by structural MRI.

yses in regulating brain structural features involved in perceptual rivalry.

The GREML method estimates SNP heritability with assumptions different from those in twin studies. Our results showed that, $\sim 25 \%$ of the phenotypic variance in spontaneous perceptual rivalry could be explained by common SNPs. The estimates for BR reached significance, validating the conclusion of nonzero heritability for perceptual rivalry. Previously, several twin studies explored genetic contributions to perceptual rivalry, and suggested the twin heritability of BR and $\mathrm{NC}$ to be $\sim 50 \%$ (Miller et al., 2010; Shannon et al., 2011; Wang et al., 2014). It is approximately twice the SNP-based heritability measured in our study. The smaller heritability estimate via the SNP-based method than via twin-based studies could be due to the genotyped SNPs being only part of the overall genetic diversity. Contributions of many low-frequency variants were not measured. There may exists incomplete linkage between the genotyped markers and real causal variants (Yang et al., 2010). We also acknowledge that, because the test-retest reliability for the behavioral phenotypes was not systematically examined, potential random variations in our behavioral measurements might contribute to this lower SNP heritability.

It is possible that BR rate might take time to stabilize, though subjects had already taken 1 min training with the rivalry stimulus. Therefore, we performed additional analyses with the mean switching rate of only the last four experimental trials in the BR task. After quality control, two SNPs reached genome-wide significance level at the discovery stage, namely rs199954060 (chr12: 8985184delC, $p=3.4 \times 10^{-12}$ ) and rs144173227 (chr17: $79714232 \mathrm{C}>\mathrm{T}, p=2.7 \times 10^{-8}$ ), but they were not replicated. $73 \%$ of the SNPs with uncorrected $p<0.05$ for BR rate averaged across all the eight trials also showed uncorrected $p<0.05$ for that averaged across the last four trials. Furthermore, the relative ranking of $p$ values from GWAS of the last four trials was similar to that from GWAS of all the eight trials (Spearman's correlation for the two sets of $p$ values was 0.61 ). Also, there was a high correlation between the average switching rates for the first four trials and the last four trials $(r=0.81)$. However, this correlation is not so high as that in Miller et al. (2010) between their blocks 2 and $3(r=0.93)$, suggesting that some degree of switching rate stabilization might occur in the first few trials of BR viewing.

The successfully replicated SNP rs75595941 for VOLUNTARY is located in an intron of ADGRB3, a p53-target gene that encodes a brain-specific angiogenesis inhibitor and regulates synaptogenesis and dendritic spine formation (Kaur et al., 2003; Lanoue et al., 2013). ADGRB3 is overexpressed in the frontal cortex (from the Human Integrated Protein Expression Database), which is involved in top-down control (Johnston et al., 2007). ADGRB3 has been linked to psychiatric disorders such as schizophrenia (Lips et al., 2012) and bipolar disorder (McCarthy et al., 2012). Several genes suggested by multiple levels of genomic analyses, such as PRMT1, are also involved in neuronal development.

Recently, there has been a genomic study on BR in which researchers performed a single GWAS with $<1000$ participants and indicated several SNPs with $p$ values between $1 \times 10^{-7}$ and $1 \times 10^{-5}$ (but without a replication study; Bosten et al., 2015). Here, our study investigated BR and NC as well as voluntary modulation of NC in a larger sample, and we have found genome-wide significant variants that survived replication. We conducted a meta-analysis of our study and Bosten et al.'s (2015) study with all the 12 SNPs they suggested to be associated with BR $\left(p<1 \times 10^{-5}\right)$. No significant associations for the 12 SNPs were found in our study although three SNPs reached uncorrected $p=$ 0.06. The failure to replicate all the SNPs found by Bosten et al. (2015) might be due to the shorter test duration in their task and different populations in their study and ours.

It has been proposed that BR and NC may share some common biological mechanisms (Andrews and Purves, 1997; Logothetis, 1998; Carter and Pettigrew, 2003). Based on our data, we believe that the common mechanisms are quite limited. First, these two kinds of perceptual rivalry were only weakly, albeit significantly, correlated phenotypically $(r=0.19)$. This is consistent with some previous studies (Gallagher and Arnold, 2014), but differs from Shannon et al. (2011) who reported a correlation coefficient as high as 0.47 . Second, there were only a few shared genes (Table 3-5, available at https://doi.org/ 10.1523/JNEUROSCI.1970-17.2018.t3-5) and pathways revealed by the genomic analyses.

A major limitation of this study is the small sample size (by the standards of genetic research), which reduces the power to detect association signals with a relatively small effect size and may lead to inaccurate SNP heritability estimation. So the suggestive findings from this study need replication with much larger sample sizes. A second limitation is the gender imbalance in the sample, which might introduce a sex factor into genetic associations. It would be better to recruit a more gender-balanced cohort for future replication studies. A third limitation is that mixed perceptual states commonly occur in the BR task but they were not recorded in the current study. Before the analyses, we excluded those participants who experienced persistent mixed percepts. The remaining participants were instructed to classify mixed percept into either perceptual state based on which image occupied the majority of the viewed stimulus field. This response protocol differed from the twin study by Miller et al. (2010) and this difference may have affected our heritability and association results. Future research can examine the relevance of recording and excluding mixed perceptual states and whether the duration of mixed percepts might itself be a parameter of interest in clinical conditions (as appears to be the case in autism; see Introduction). A fourth limitation is that subjects were only instructed to increase their perceptual switching rate for measuring voluntary 
modulation. In this regard, it is noteworthy that Hunt and Guilford (1933) reported the difference between Necker cube switching rates in bipolar versus control subjects was even greater when subjects were instructed to slow down the perceptual reversal (i.e., the opposite of our instruction). We chose to focus on the speed up instruction to avoid possible confounding factors associated with the slow down instruction, but future studies examining the genetics underlying voluntary modulation of perceptual rivalry could assess the slow down process. A fifth limitation is that VOLUNTARY phenotype shows no SNP heritability but has genome-wide significant threshold SNPs. The reason for this conundrum could be due to the relatively small sample size and the low imputation INFO score for genome-wide significant SNPs that might smear associations and result in no consolidated peaks (Fig. 4). Future investigation on the heritability of VOLUNTARY is needed.

Perceptual rivalry has been implicated as a potential endophenotype for bipolar disorder (Pettigrew and Miller, 1998; Ngo et al., 2011; Vierck et al., 2013). Several genes associated with perceptual rivalry in our study are suggested to be associated with bipolar disorder by literature, such as BR-related gene NFE2L2 (Rizak et al., 2014) and NC-related gene SRI (Beasley et al., 2006), which further supports the relationship between perceptual rivalry and bipolar disorder. Investigation of the genetics of perceptual rivalry may contribute to our understanding of molecular mechanisms underlying psychiatric disorders. Deficits in voluntary control were found in many psychological disorders such as bipolar disorder (Blumberg et al., 2003; Dickstein et al., 2004). Several candidate genes associated with voluntary modulation strength in our study have also been implicated in these disorders, such as ADGRB3 (McCarthy et al., 2012). This raises the possibility that measuring voluntary modulation strength through perceptual rivalry tasks like the Necker cube might also be used as an endophenotype for these disorders, and exploring the genetics underlying voluntary modulation strength might advance our understanding of human psychological disorders. Nevertheless, it is worthwhile to perform larger-scale genomic studies to further validate the relationship between psychiatric disorders and the candidate genes reported in our study.

In conclusion, this study is currently the largest and the first multilevel GWAS on perceptual rivalry and its voluntary modulation. We investigated two important kinds of perceptual rivalry, BR and NC. Several genetic elements were discovered through genomic approaches and their biological functions were implicated by structural brain imaging, including some genes related to neuronal growth and psychiatric disorders. This research supports the application of genomic analyses in investigating biological mechanisms underlying visual cognition in the healthy and disordered brain.

\section{References}

Aafjes M, Hueting JE, Visser P (1966) Individual and interindividual differences in binocular retinal rivalry in man. Psychophysiology 3:18-22. CrossRef Medline

Allen ML, Chambers A (2011) Implicit and explicit understanding of ambiguous figures by adolescents with autism spectrum disorder. Autism 15:457-472. CrossRef Medline

Andrews TJ, Purves D (1997) Similarities in normal and binocularly rivalrous viewing. Proc Natl Acad Sci U S A 94:9905-9908. CrossRef Medline

Bach M (1996) The "Freiburg visual acuity test": automatic measurement of visual acuity. Optom Vis Sci 73:49-53. CrossRef Medline

Barrett JC, Fry B, Maller J, Daly MJ (2005) Haploview: analysis and visualization of LD and haplotype maps. Bioinformatics 21:263-265. CrossRef Medline

Beasley CL, Pennington K, Behan A, Wait R, Dunn MJ, Cotter D (2006)
Proteomic analysis of the anterior cingulate cortex in the major psychiatric disorders: evidence for disease-associated changes. Proteomics 6:3414-3425. CrossRef Medline

Bisiach E, Ricci R, Lai E, De Tanti A, Inzaghi MG (1999) Unilateral neglect and disambiguation of the Necker cube. Brain 122:131-140. CrossRef Medline

Blake R, Logothetis N (2002) Visual competition. Nat Rev Neurosci 3:1321. CrossRef Medline

Blumberg HP, Martin A, Kaufman J, Leung HC, Skudlarski P, Lacadie C, Fulbright RK, Gore JC, Charney DS, Krystal JH, Peterson BS (2003) Frontostriatal abnormalities in adolescents with bipolar disorder: preliminary observations from functional MRI. Am J Psychiatry 160:1345-1347. CrossRef Medline

Bosten JM, Goodbourn PT, Lawrance-Owen AJ, Bargary G, Hogg RE, Mollon JD (2015) A population study of binocular function. Vision Res 110:3450. CrossRef Medline

Brainard DH (1997) The psychophysics toolbox. Spat Vis 10:433-436. CrossRef Medline

Brascamp J, Sterzer P, Blake R, Knapen T (2018) Multistable perception and the role of the frontoparietal cortex in perceptual inference. Annu Rev Psychol 69:77-103. CrossRef Medline

Bulik-Sullivan B, Loh PR, Finucane HK, Ripke S, Yang J, Patterson N, Daly MJ, Price AL, Neale BM (2015) LD score regression distinguishes confounding from polygenicity in genome-wide association studies. Nat Genet 47:291-295. CrossRef Medline

Carter OL, Pettigrew JD (2003) A common oscillator for perceptual rivalries. Perception 32:295-305. CrossRef Medline

Carter OL, Pettigrew JD, Hasler F, Wallis GM, Liu GB, Hell D, Vollenweider FX (2005a) Modulating the rate and rhythmicity of perceptual rivalry alternations with the mixed 5-HT2A and 5-HT1A agonist psilocybin. Neuropsychopharmacology 30:1154-1162. CrossRef Medline

Carter OL, Presti DE, Callistemon C, Ungerer Y, Liu GB, Pettigrew JD (2005b) Meditation alters perceptual rivalry in Tibetan Buddhist monks. Curr Biol 15:R412-R413. CrossRef Medline

Cohen L (1959) Perception of reversible figures after brain injury. AMA Arch Neurol Psychiatry 81:765-775. CrossRef Medline

de Graaf TA, de Jong MC, Goebel R, van Ee R, Sack AT (2011) On the functional relevance of frontal cortex for passive and voluntarily controlled bistable vision. Cereb Cortex 21:2322-2331. CrossRef Medline

Delaneau O, Marchini J, Zagury JF (2012) A linear complexity phasing method for thousands of genomes. Nat Methods 9:179-181. CrossRef Medline

Dickstein DP, Treland JE, Snow J, McClure EB, Mehta MS, Towbin KE, Pine DS, Leibenluft E (2004) Neuropsychological performance in pediatric bipolar disorder. Biol Psychiatry 55:32-39. CrossRef Medline

Ellis SR, Stark L (1978) Eye movements during the viewing of Necker cubes. Perception 7:575-581. CrossRef Medline

Enoksson P (1963) Binocular rivalry and monocular dominance studied with optokinetic nystagmus. Acta Ophthalmologica 41:544-563. CrossRef Medline

Fagard J, Sacco S, Yvenou C, Domellöf E, Kieffer V, Tordjman S, Moutard ML, Mamassian P (2008) The role of the corpus callosum in the perception of reversible figures in children. Vision Res 48:2451-2455. CrossRef Medline

Frässle S, Sommer J, Jansen A, Naber M, Einhäuser W (2014) Binocular rivalry: frontal activity relates to introspection and action but not to perception. J Neurosci 34:1738-1747. CrossRef Medline

Gallagher R, Arnold DH (2014) Interpreting the temporal dynamics of perceptual rivalries. Perception 43:1239-1248. CrossRef Medline

Gauderman WJ, Morrison JM (2006) QUANTO 1.1: a computer program for power and sample size calculations for genetic-epidemiology studies. Available at http://biostats.usc.edu/Quanto.html. Accessed on 5 July 2016.

Ge S, Ueno S, Iramina K (2007) The rTMS effect on perceptual switching of ambiguous figures. Conf Proc IEEE Eng Med Biol Soc 47:43-46. CrossRef

George RW (1936) The significance of the fluctuations experienced in observing ambiguous figures and in binocular rivalry. J Gen Psychol 15:3961. CrossRef

Howie BN, Donnelly P, Marchini J (2009) A flexible and accurate genotype imputation method for the next generation of genome-wide association studies. PLoS Genet 5:e1000529. CrossRef Medline

Howie B, Fuchsberger C, Stephens M, Marchini J, Abecasis GR (2012) Fast 
and accurate genotype imputation in genome-wide association studies through pre-phasing. Nat Genet 44:955-959. CrossRef Medline

Hunt JM, Guilford JP (1933) Fluctuation of an ambiguous figure in dementia praecox and in manic-depressive patients. J Abnorm Soc Psychol 27: 443-452. CrossRef

Inui T, Tanaka S, Okada T, Nishizawa S, Katayama M, Konishi J (2000) Neural substrates for depth perception of the Necker cube: a functional magnetic resonance imaging study in human subjects. Neurosci Lett 282: 145-148. CrossRef Medline

Ishizu T, Zeki S (2014) Varieties of perceptual instability and their neural correlates. Neuroimage 91:203-209. CrossRef Medline

İsoğlu-Alkac U, Strüber D (2006) Necker cube reversals during long-term EEG recordings: sub-bands of alpha activity. Int J Psychophysiol 59:179189. CrossRef Medline

Johnston K, Levin HM, Koval MJ, Everling S (2007) Top-down controlsignal dynamics in anterior cingulate and prefrontal cortex neurons following task switching. Neuron 53:453-462. CrossRef Medline

Kanai R, Bahrami B, Rees G (2010) Human parietal cortex structure predicts individual differences in perceptual rivalry. Curr Biol 20:1626-1630. CrossRef Medline

Kaur B, Brat DJ, Calkins CC, Van Meir EG (2003) Brain angiogenesis inhibitor 1 is differentially expressed in normal brain and glioblastoma independently of p53 expression. Am J Pathol 162:19-27. CrossRef Medline

Knapen T, Brascamp J, Pearson J, van Ee R, Blake R (2011) The role of frontal and parietal brain areas in bistable perception. J Neurosci 31: 10293-10301. CrossRef Medline

Kornmeier J, Bach M (2004) Early neural activity in Necker-cube switching: evidence for low-level processing of a gestalt phenomenon. Psychophysiology 41:1-8. CrossRef Medline

Kornmeier J, Hein CM, Bach M (2009) Multistable perception: when bottom-up and top-down coincide. Brain Cogn 69:138-147. CrossRef Medline

Lanoue V, Usardi A, Sigoillot SM, Talleur M, Iyer K, Mariani J, Isope P, Vodjdani G, Heintz N, Selimi F (2013) The adhesion-GPCR BAI3, a gene linked to psychiatric disorders, regulates dendrite morphogenesis in neurons. Mol Psychiatry 18:943-950. CrossRef Medline

Leopold DA, Logothetis NK (1996) Activity changes in early visual cortex reflect monkeys' percepts during binocular rivalry. Nature 379:549-553. CrossRef Medline

Liebert RM, Burk B (1985) Voluntary control of reversible figures. Percept Mot Skills 61:1307-1310. CrossRef Medline

Lips ES, Cornelisse LN, Toonen RF, Min JL, Hultman CM; the International Schizophrenia Consortium, Holmans PA, O'Donovan MC, Purcell SM, Smit AB, Verhage M, Sullivan PF, Visscher PM, Posthuma D (2012) Functional gene group analysis identifies synaptic gene groups as risk factor for schizophrenia. Mol Psychiatry 17:996-1006. CrossRef Medline

Liu JZ, McRae AF, Nyholt DR, Medland SE, Wray NR, Brown KM; AMFS Investigators, Hayward NK, Montgomery GW, Visscher PM, Martin NG, Macgregor S (2010) A versatile gene-based test for genome-wide association studies. Am J Hum Genet 87:139-145. CrossRef Medline

Logothetis NK (1998) Single units and conscious vision. Philos Trans R Soc Lond B Biol Sci 353:1801-1818. CrossRef Medline

Lumer ED, Friston KJ, Rees G (1998) Neural correlates of perceptual rivalry in the human brain. Science 280:1930-1934. CrossRef Medline

Marchini J, Howie B, Myers S, McVean G, Donnelly P (2007) A new multipoint method for genome-wide association studies via imputation of genotypes. Nat Genet 39:906-913. CrossRef Medline

Mathes B, Strüber D, Stadler MA, Basar-Eroglu C (2006) Voluntary control of Necker cube reversals modulates the EEG delta- and gamma-band response. Neurosci Lett 402:145-149. CrossRef Medline

McCarthy MJ, Nievergelt CM, Kelsoe JR, Welsh DK (2012) A survey of genomic studies supports association of circadian clock genes with bipolar disorder spectrum illnesses and lithium response. PLoS One 7:e32091. CrossRef Medline

Meenan JP, Miller LA (1994) Perceptual flexibility after frontal or temporal lobectomy. Neuropsychologia 32:1145-1149. CrossRef Medline

Megumi F, Bahrami B, Kanai R, Rees G (2015) Brain activity dynamics in human parietal regions during spontaneous switches in bistable perception. Neuroimage 107:190-197. CrossRef Medline

Meng M, Tong F (2004) Can attention selectively bias bistable perception? Differences between binocular rivalry and ambiguous figures. J Vis 4:539-551. CrossRef Medline
Meng M, Remus DA, Tong F (2005) Filling-in of visual phantoms in the human brain. Nat Neurosci 8:1248-1254. CrossRef Medline

Miller SM, Liu GB, Ngo TT, Hooper G, Riek S, Carson RG, Pettigrew JD (2000) Interhemispheric switching mediates perceptual rivalry. Curr Biol 10:383-392. CrossRef Medline

Miller SM, Gynther BD, Heslop KR, Liu GB, Mitchell PB, Ngo TT, Pettigrew JD, Geffen LB (2003) Slow binocular rivalry in bipolar disorder. Psychol Med 33:683-692. CrossRef Medline

Miller SM, Hansell NK, Ngo TT, Liu GB, Pettigrew JD, Martin NG, Wright MJ (2010) Genetic contribution to individual variation in binocular rivalry rate. Proc Natl Acad Sci U S A 107:2664-2668. CrossRef Medline

Mishra A, Macgregor S (2015) VEGAS2: software for more flexible genebased testing. Twin Res Hum Genet 18:86-91. CrossRef Medline

Mishra A, MacGregor S (2017) A novel approach for pathway analysis of GWAS data highlights role of BMP signaling and muscle cell differentiation in colorectal cancer susceptibility. Twin Res Hum Genet 20:1-9. CrossRef Medline

Nagamine M, Yoshino A, Yamazaki M, Obara M, Sato S, Takahashi Y, Nomura S (2007) Accelerated binocular rivalry with anxious personality. Physiol Behav 91:161-165. CrossRef Medline

Nagamine M, Yoshino A, Miyazaki M, Takahashi Y, Nomura S (2008) Effects of selective 5-HT(1A) agonist tandospirone on the rate and rhythmicity of binocular rivalry. Psychopharmacology 198:279-286. CrossRef Medline

Nagamine M, Yoshino A, Miyazaki M, Takahashi Y, Nomura S (2009) Difference in binocular rivalry rate between patients with bipolar I and bipolar II disorders. Bipolar Disorders 11:539-546. CrossRef Medline

Necker LA (1832) Observations on some remarkable optical phaenomena seen in Switzerland; and on an optical phaenomenon which occurs on viewing a figure of a crystal or geometrical solid. LXI. Philos Mag Ser 3 1:329-337. CrossRef

Ngo TT, Mitchell PB, Martin NG, Miller SM (2011) Psychiatric and genetic studies of binocular rivalry: an endophenotype for bipolar disorder? Acta Neuropsychiatr 23:37-42. CrossRef

Ngo TT, Barsdell WN, Law PC, Miller SM (2013) Binocular rivalry, brain stimulation and bipolar disorder. In: The constitution of visual consciousness: lessons from binocular rivalry (Miller SM, ed), pp 211-252. Amsterdam: John Benjamins. CrossRef

Parkkonen L, Andersson J, Hämäläinen MS, Hari R (2008) Early visual brain areas reflect the percept of an ambiguous scene. Proc Natl Acad Sci U S A 105:20500-20504. CrossRef Medline

Pelton LH, Solley CM (1968) Acceleration of switchings of a Necker cube. Am J Psychol 81:585-588. CrossRef Medline

Pettigrew JD, Miller SM (1998) A "sticky" interhemispheric switch in bipolar disorder? Proc Biol Sci 265:2141-2148. CrossRef Medline

Phillipson OT, Harris JP (1984) Effects of chlorpromazine and promazine on the perception of some multi-stable visual figures. Q J Exp Psychol A 36:291-308. CrossRef Medline

Pitts MA, Gavin WJ, Nerger JL (2008) Early top-down influences on bistable perception revealed by event-related potentials. Brain Cogn 67:11-24. CrossRef Medline

Price AL, Patterson NJ, Plenge RM, Weinblatt ME, Shadick NA, Reich D (2006) Principal components analysis corrects for stratification in genome-wide association studies. Nat Genet 38:904-909. CrossRef Medline

Purcell S, Neale B, Todd-Brown K, Thomas L, Ferreira MA, Bender D, Maller J, Sklar P, de Bakker PI, Daly MJ, Sham PC (2007) PLINK: a tool set for whole-genome association and population-based linkage analyses. Am J Hum Genet 81:559-575. CrossRef Medline

Raz A, Lamar M, Buhle JT, Kane MJ, Peterson BS (2007) Selective biasing of a specific bistable-figure percept involves fMRI signal changes in frontostriatal circuits: a step toward unlocking the neural correlates of topdown control and self-regulation. Am J Clin Hypn 50:137-156. CrossRef Medline

Ricci C, Blundo C (1990) Perception of ambiguous figures after focal brain lesions. Neuropsychologia 28:1163-1173. CrossRef Medline

Rizak J, Tan H, Zhu H, Wang JF (2014) Chronic treatment with the moodstabilizing drug lithium up-regulates nuclear factor E2-related factor 2 in rat pheochromocytoma PC12 cells in vitro. Neuroscience 256:223-229. CrossRef Medline

Robertson CE, Kravitz DJ, Freyberg J, Baron-Cohen S, Baker CI (2013) 
Slower rate of binocular rivalry in autism. J Neurosci 33:16983-16991. CrossRef Medline

Ropar D, Mitchell P, Ackroyd K (2003) Do children with autism find it difficult to offer alternative interpretations to ambiguous figures? Br J Dev Psychol 21:387-395. CrossRef

Scocchia L, Valsecchi M, Triesch J (2014) Top-down influences on ambiguous perception: the role of stable and transient states of the observer. Front Hum Neurosci 8:979. CrossRef Medline

Shannon RW, Patrick CJ, Jiang Y, Bernat E, He S (2011) Genes contribute to the switching dynamics of bistable perception. J Vis 11(3):8 1-7. CrossRef Medline

Shen L, Zeng ZL, Huang PY, Li Q, Mu J, Huang XQ, Lui S, Gong QY, Xie P (2009) Temporal cortex participates in spontaneuous perceptual switching. Neuroreport 20:647-651. CrossRef Medline

Slotnick SD, Yantis S (2005) Common neural substrates for the control and effects of visual attention and perceptual bistability. Brain Res Cogn Brain Res 24:97-108. CrossRef Medline

Sterzer P, Kleinschmidt A (2007) A neural basis for inference in perceptual ambiguity. Proc Natl Acad Sci U S A 104:323-328. CrossRef Medline

Sterzer P, Kleinschmidt A, Rees G (2009) The neural basis of multistable perception. Trends Cogn Sci 13:310-318. CrossRef Medline

Strüber D, Stadler M (1999) Differences in top-down influences on the switching rate of different categories of reversible figures. Perception 28: 1185-1196. CrossRef Medline

Strüber D, Başar-eroglu C, Miener M, Stadler M (2001) EEG gamma-band response during the perception of Necker cube reversals. Vis Cogn 8:609621. CrossRef

Toppino TC (2003) Reversible-figure perception: mechanisms of intentional control. Percept Psychophys 65:1285-1295. CrossRef Medline

Van de Cruys S, Schouten B, Wagemans J (2013) An anxiety-induced bias in the perception of a bistable point-light walker. Acta Psychol (Amst) 144: 548-553. CrossRef Medline

van Ee R, van Dam L, Brouwer GJ (2005) Voluntary control and the dynamics of perceptual bistability. Vis Res 45:41-55. CrossRef Medline

van Loon AM, Knapen T, Scholte HS, St John-Saaltink E, Donner TH, Lamme VA (2013) GABA shapes the dynamics of bistable perception. Curr Biol 23:823-827. CrossRef Medline

Vierck E, Porter RJ, Luty SE, Moor S, Crowe MT, Carter JD, Inder ML, Joyce PR (2013) Further evidence for slow binocular rivalry rate as a trait marker for bipolar disorder. Aust N Z J Psychiatry 47:371-379. CrossRef Medline

Visscher PM, Hemani G, Vinkhuyzen AA, Chen GB, Lee SH, Wray NR,
Goddard ME, Yang J (2014) Statistical power to detect genetic (co)variance of complex traits using SNP data in unrelated samples. PLoS Genet 10:e1004269. CrossRef Medline

Wang M, Arteaga D, He BJ (2013) Brain mechanisms for simple perception and bistable perception. Proc Natl Acad Sci U S A 110:E3350-E3359. CrossRef Medline

Wang Y, Wang L, Xu Q, Liu D, Jiang Y (2014) Domain-specific genetic influence on visual-ambiguity resolution. Psychol Sci 25:1600-1607. CrossRef Medline

Washburn M, Gillette A (1933) Studies from the psychological laboratory of Vassar college: LXII. Motor factors in voluntary control of cube perspective fluctuations and retinal rivalry fluctuations. Am J Psychol 45:315319. CrossRef

Watanabe T, Masuda N, Megumi F, Kanai R, Rees G (2014) Energy landscape and dynamics of brain activity during human bistable perception. Nat Commun 5:4765. CrossRef Medline

Weilnhammer VA, Ludwig K, Hesselmann G, Sterzer P (2013) Frontoparietal cortex mediates perceptual transitions in bistable perception. J Neurosci 33:16009-16015. CrossRef Medline

Wimmer MC, Doherty MJ (2010) Children with autism's perception and understanding of ambiguous figures: evidence for pictorial metarepresentation: a research note. Br J Dev Psychol 28:627-641. CrossRef Medline

Windmann S, Wehrmann M, Calabrese P, Güntürkün O (2006) Role of the prefrontal cortex in attentional control over bistable vision. J Cogn Neurosci 18:456-471. CrossRef Medline

Xu H, Han C, Chen M, Li P, Zhu S, Fang Y, Hu J, Ma H, Lu HD (2016) Rivalry-like neural activity in primary visual cortex in anesthetized monkeys. J Neurosci 36:3231-3242. CrossRef Medline

Yang J, Benyamin B, McEvoy BP, Gordon S, Henders AK, Nyholt DR, Madden PA, Heath AC, Martin NG, Montgomery GW, Goddard ME, Visscher PM (2010) Common SNPs explain a large proportion of the heritability for human height. Nat Genet 42:565-569. CrossRef Medline

Yang J, Lee SH, Goddard ME, Visscher PM (2011) GCTA: a tool for genomewide complex trait analysis. Am J Hum Genet 88:76-82. CrossRef Medline

Zheng J, Erzurumluoglu AM, Elsworth BL, Kemp JP, Howe L, Haycock PC, Hemani G, Tansey K, Laurin C, Laurin C, Pourcain BS, Warrington NM, Finucane HK, Price AL, Bulik-Sullivan BK, Anttila V, Paternoster L, Gaunt TR, Evans DM, Neale BM (2017) LD hub: a centralized database and web interface to perform LD score regression that maximizes the potential of summary level GWAS data for SNP heritability and genetic correlation analysis. Bioinformatics 33:272-279. CrossRef Medline 